\title{
Association Between udp-glucuronosyltransferase $1 a 1$ (ugt1a1) Gene Polymorphism, (c.-3279t>g) and Phototherapy among Glucose-6-Phosphate Dehydrogenase (g6pd)-Deficient Neonates
}

\author{
Fook-Choe Cheah*1, Fei-Liang Wong ${ }^{1}$, Azlin Ithnin ${ }^{2}$ and Ainoon Othman ${ }^{3}$ \\ ${ }^{1}$ Department of Pediatrics, Universiti Kebangsaan Malaysia Medical Centre, Malaysia \\ ${ }^{2}$ Department of Pathology, Faculty of Medicine, Universiti Kebangsaan Malaysia Medical Centre, Malaysia \\ ${ }^{3}$ Department of Pathology, Faculty of Medicine, Universiti Sains Islam Malaysia, Malaysia
}

Received: January 22, 2018; Published: January 31, 2018

*Corresponding author: Fook-Choe Cheah, Department of Paediatrics, Universiti Kebangsaan Malaysia, Medical Centre, Kuala Lumpur, Malaysia, Tel: 60-3-91455391; Email: cheahfc@ppukm.ukm.edu.my

\begin{abstract}
Hyperbilirubinemia is one of the most commonly encountered conditions even in otherwise healthy newborn infants in the first week of life. There is emerging evidence that polymorphism of genes involved in bilirubin conjugation such as the UDP-glucuronosyltransferase 1A1 (UGT1A1) may contribute to some infants developing neonatal jaundice, significant enough to require phototherapy. In many parts of the world, glucose-6-phosphate dehydrogenase (G6PD) deficiency is also a major cause of severe neonatal hyperbilirubinemia. Some genetic polymorphisms of UGT1A1 and G6PD are associated with more severe hyperbilirubinemia. Recently, the c.-3279T>A mutation in the Phenobarbital responsive enhancer module was reported to decrease UGT1A1 transcriptional activity and associated with more neonatal jaundice. However, there are limited reports of co-inheritance of these two gene variants, whether this predisposes infants to greater risk for phototherapy. We studied a total of 133 infants and our results indicate that the occurrence of UGT1A1 allele c.-3279T >G was similar in G6PD deficient infants whether or not they required phototherapy in the first five days of life. Co-inheriting both the c.-3279T $>$ G and G6PD variants in these deficient infants also did not significantly elevate the peak serum bilirubin in the first week.
\end{abstract}

Abbreviations: AAP: American Academy of Pediatrics; FST: Fluorescent spot test; G6PD: Glucose-6-phosphate dehydrogenate; UGT1A1: Uridine 5'-diphosphate glucuronosyl transferase 1A1; WHO: World Health Organization

\section{Introduction}

Glucose-6-phosphate dehydrogenase (G6PD) deficiency affects 400 million people worldwide with an estimated global prevalence of 4.9\% [1]. This X-linked inherited enzyme deficiency is a recognized cause of neonatal jaundice, severe enough to lead to kernicterus. Across the Asia-Pacific region, the risk of such complications justifies some countries investing resources to include routine testing in their national neonatal screening programmes [2]. The fluorescent spot test (FST) is adopted by most countries, but this test at best a semi-quantitative measure, is not predictive of severity based on the WHO classification [3]. that groups variants according to their residual enzyme activity levels. A recent study [4]. Showed that G6PD enzyme activity $<6.76$ $\mathrm{U} / \mathrm{g} \mathrm{Hb}$ and the mutation at nucleotide $1388 \mathrm{G}>\mathrm{A}$ were independent risk factors for phototherapy in newborn infants within the first week of life. Another factor that increases the risk of significant neonatal hyperbilirubinemia particularly in the Asian population is genetic polymorphism of the uridine 5'-diphosphate glucuronosyl transferase 1A1 (UGT1A1), such as homozygous c211G>A, among newborn infants of Chinese descent [5]. Of note, co-inheritance of this gene variant in G6PD deficient neonates was reported to increase the severity of neonatal jaundice [6].

In another study [7]. The c.-3279T $>\mathrm{G}$ mutation, reportedly also common in this region, was shown to be a risk factor for neonatal hyperbilirubinemia. Located in the region of the Phenobarbital responsive enhancer module, this mutation in has been reported to decrease transcription of the UGT1A1 promoter by $60 \%$ [8]. However, the combined effect of c.-3279T $>$ G with G6PD mutations on the severity of neonatal hyperbilirubinemia has not been 
reported. It is also unclear if the c. $-3279 \mathrm{~T}>\mathrm{G}$ mutation presence increases the risk of G6PD deficient infants developing severe jaundice to require phototherapy. To answer these questions, we studied G6PD deficient infants, as detected by the FST, and who were divided into two groups, whether they received phototherapy or not during the first five days of life, the mandatory minimum duration of in-hospital monitoring as per protocol. Phototherapy intervention for hyperbilirubinemia was based on the American Academy of Pediatrics (AAP) norm gram [9].

This study involved a sub-population of patients from a recently published principal trial [4]. That was approved by the hospital research and ethics committee (Reg. No. UKM FF-03FRGS0038-2010). Eligible infants were selected randomly using a cluster sampling method. Infants of gestation lower than 36 weeks gestation and with other risks for hyperbilirubinemia such as ABO incompatibility were excluded. Parental consent was obtained before each infant was enrolled. Investigations that were part of the principal trial included serum bilirubin, G6PD enzyme activity levels (OSMMR-D G6PD assay kit with hemoglobin normalization; R \& D Diagnostics, Holargos, Greece) and blood spots on filter paper processed for DNA extraction using the TaqMan ${ }^{\circledR}$ Sample-to-SNP ${ }^{\mathrm{T}}$ kit (Applied Biosystem, Foster City, $\mathrm{CA}$ ) to test for the ten common G6PD mutations (c.871G>A, c. $487 \mathrm{G}>\mathrm{A}$, c. $1388 \mathrm{G}>\mathrm{A}$, c. $1376 \mathrm{G}>\mathrm{T}$, c. $95 \mathrm{~A}>\mathrm{G}$, c. $1024 \mathrm{C}>\mathrm{T}$, c. $563 \mathrm{C}>\mathrm{T}$, c. $392 \mathrm{G}>\mathrm{T}$, c. $1003 \mathrm{G}>\mathrm{A}$, and c. $592 \mathrm{C}>$ T) in our population. For this nested study, a total of 133 infants with complete genotyping for the above ten mutations and the UGT1A1 variant, c.-3279T $>$ G were compared between two groups based on whether phototherapy was required (Table 1).

Table 1: c.-3279T>G UGT1A1 mutation in G6PD deficient infants and the relationship with phototherapy intervention in the first week of life.

\begin{tabular}{|c|c|c|c|}
\hline $\begin{array}{c}\text { Infant } \\
\text { characteristics }\end{array}$ & $\begin{array}{c}\text { No Phototherapy } \\
(n=66)\end{array}$ & $\begin{array}{l}\text { Phototherapy } \\
\quad(n=67)\end{array}$ & p-value \\
\hline $\begin{array}{l}\text { Gestation, median } \\
\text { (weeks) (IQR) }\end{array}$ & $39(38-40)$ & $38(38-39)$ & 0.095 \\
\hline $\begin{array}{l}\text { Birth weight, mean } \\
\text { (grams)(SD) }\end{array}$ & $3134(443)$ & 3021 (389) & 0.120 \\
\hline $\begin{array}{l}\text { Ethnicity, Malay (n) } \\
(\%)\end{array}$ & $50(76)$ & $44(66)$ & 0.201 \\
\hline Gender, Male (n)(\%) & $49(74)$ & $61(91)$ & 0.010 \\
\hline $\begin{array}{c}\text { G6PD enzyme activity, } \\
\text { median }(\mathrm{U} / \mathrm{g} \mathrm{Hb}) \\
(\mathrm{IQR})\end{array}$ & $4.0(3.3-6.5)$ & $3.5(2.7-4.2)$ & 0.004 \\
\hline $\begin{array}{l}\text { Peak serum bilirubin, } \\
\text { median(micromol/L) } \\
\text { (IQR) }\end{array}$ & $204(163-235)$ & $272(257-297)$ & $<0.001$ \\
\hline \multicolumn{4}{|c|}{ Gene variants } \\
\hline \multicolumn{4}{|l|}{ c.-3279T>G UGT1A1 } \\
\hline Homozygous (\%) & $9(14)$ & $11(16)$ & \\
\hline Heterozygous (\%) & $29(44)$ & $30(45)$ & 0.868 \\
\hline No mutation (\%) & $28(42)$ & $26(39)$ & \\
\hline \multicolumn{4}{|c|}{ Co-inheritance of gene variants } \\
\hline $\begin{array}{l}\text { C.-3279T }>\text { G and } \\
\text { G6PD* }(\%)\end{array}$ & $31(47)$ & $31(47)$ & 0.519 \\
\hline
\end{tabular}

There were no significant differences between groups with reference to gestation, birth weight and ethnicity. Majority of the infants were of Malay descent, also the predominant ethnic group of patients being seen in this hospital. There were significantly more male infants, lower G6PD enzyme activity and higher peak serum bilirubin in the group that required phototherapy. Our results showed that having the UGT1A1 variant, c.-3279T >G, either homozygous or heterozygous, was not associated with significantly more G6PD deficient neonates requiring phototherapy. This result is novel, further to the study by Yusoff [7]. That did not discern if the c.-3279 mutations associated with increased neonatal hyperbilirubinemia, rendered the infants more at risk for phototherapy. In contrast, Kanai [10]. Reported that there was no difference in allele frequency of c.-3279T $>\mathrm{G}$ amongst Japanese infants with or without neonatal jaundice. The variability in outcomes may be attributed to the criterion used in these previous studies to define neonates to have significant hyperbilirubinemia which was based on a fixed cut-off value of 250 micromol/L. For our study, we used a different approach to relate the effects of the mutation on clinical outcome which is the need for phototherapy based on a widely adopted reference normogram. The median serum bilirubin for infants with or without phototherapy was significantly different (272 micromol/L versus $204 \mathrm{micromol} / \mathrm{L}$, respectively; $\mathrm{p}<0.001$ ).

Furthermore, we observed that the occurrence of both c.$3279 \mathrm{~T}>\mathrm{G}$ and G6PD variants were not different whether the babies required phototherapy or not ( $47 \%$ in either group) (Table 1). Infants with both the c.-3279T $>\mathrm{G}$ and G6PD variants, had similar mean peak serum bilirubin level to those without this coinheritance $(273+31 \mathrm{micromol} / \mathrm{L}$ versus $280+36 \mathrm{micromol} / \mathrm{L}$, respectively; $p=0.402$ ). To our knowledge this is the first report associating both UGT1A1 polymorphism and G6PD variants on the need for phototherapy in neonates with hyperbilirubinemia. Having the c. $-3279 \mathrm{~T}>\mathrm{G}$ allele does not appear to pose added risk for phototherapy in infants who are G6PD deficient. Co-inheriting both the c.-3279T>G and G6PD mutations also did not increase significantly the peak serum bilirubin of G6PD deficient infants in the first five days of life. These preliminary findings, we hope will lead to future multi-center trials to study UGT1A1 polymorphisms and G6PD gene variants of larger populations of infants with diverse ethnic backgrounds who are jaundiced and require phototherapy.

We would like to thank Ms Angeline Loh Mee-Ling and the nurses, doctors and staff in the post-natal wards and molecular haematology laboratory of the UKM Medical Centre for their technical assistance. This study received financial assistance from the Fundamental Research Grant Scheme (UKM-FF-03FRGS0038-2010) of the Ministry of Higher Education of Malaysia.

\section{References}

1. Nkhoma ET, Poole C, Vannappagari V, Hall SA, Beutler E (2009) The global prevalence of glucose-6-phosphate dehydrogenase deficiency: a systematic review and metaanalysis. Blood Cells Mol 42: 267-278.

2. Padilla CD, Therrell BL (2007) Newborn screening in the Asia Pacific region. J Inherit Metab Dis 30: 490-506.

\section{Acknowledgement}


3. (1989) WHO Working Group. Glucose-6-phosphate dehydrogenase deficiency. Bull World Health Organ 67: 601-611.

4. Wong FL, Ithnin A, Othman A, Cheah FC (2017) Glucose-6-phosphate dehydrogenase (G6PD)-deficient infants: Enzyme activity and gene variants as risk factors for phototherapy in the first week of life. J Paediatr Child Health 53: 705-710.

5. Boo NY, Wong FL, Wang MK, Ainoon O (2009) Homozygous variant of UGT1A1 gene mutation and severe neonatal hyperbilirubinemia. Pediatr Int 51(4): 488-493.

6. Huang CS, Chang PF, Huang MJ, Chen ES, Chen WC (2002) Glucose-6phosphate dehydrogenase deficiency, the UDP-glucuronosyl transferase 1A1 gene, and neonatal hyperbilirubinemia. Gastroenterology 123: 127133.

7. Yusoff S, Takeuchi A, Ashi C, Tsukada M, Ma'amor NH, et al. (2010) A polymorphic mutation, c.-3279t>g, in the UGT1A1 promoter is a risk factor for neonatal jaundice in the Malay population. Pediatr Res 67: 401-406.

8. Sugatani J, Yamakawa K, Yoshinari $\mathrm{K}$, Machida $\mathrm{T}$, Takagi $\mathrm{H}$, et al. (2002) Identification of a defect in the UGT1A1 gene promoter and its association with hyperbilirubinemia. Biochem Biophys Res Commun 292:492-497.

9. (2004) American Academy of Pediatrics Subcommittee on Hyperbilirubinemia. Management of hyperbilirubinemia in the newborn infant 35 or more weeks of gestation. Pediatr 114(1): 297-316.

10. Kanai M, Kijima K, Shirahata E, Sasaki A, Akaba K, et al. (2005) Neonatal hyperbilirubinemia and the bilirubin uridine diphosphateglucuronosyltransferase gene: the common $-3263 \mathrm{~T}>\mathrm{G}$ mutation of phenobarbital response enhancer module is not associated with the neonatal hyperbilirubinemia in Japanese. Pediatr Int 47: 137-141.

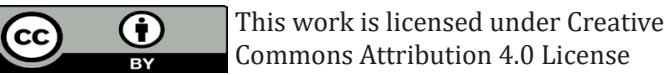

Submission Link: http://biomedres.us/submit-manuscript.php

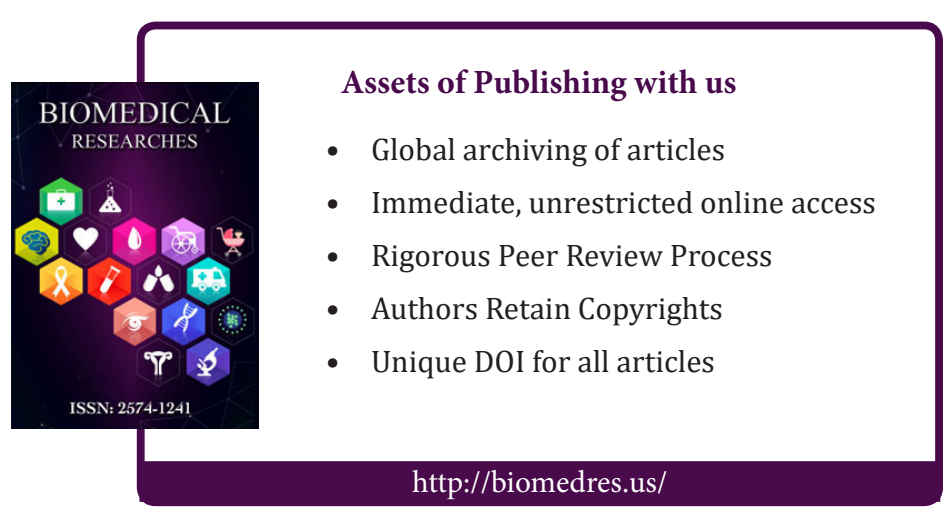

